\title{
NMDA-Sensitive Glutamate Antagonism: A Human Model for Psychosis
}

\author{
Adrienne C. Lahti, M.D., Henry H. Holcomb, M.D., Xue-Min Gao, Ph.D., \\ and Carol A. Tamminga, M.D.
}

The use of animal models for the study of psychosis and new treatment development is inadequate in assessing target psychotic symptoms because animals lack an ability to use language. Despite this deficiency, new antidopaminergic antipsychotic drugs have still become available. However, even these new antipsychotics, although substantially better than the conventional compounds, do not "cure" psychosis or normalize schizophrenic symptoms. The need for new treatment strategies is apparent. The value of a human model, where language is available to describe target symptoms, is clear. Currently, there is an opportunity to use the mild psychotomimetic symptoms induced by a minimal dose of ketamine in normal humans as a model of psychosis. The mental symptoms in this model resemble some of the symptoms of schizophrenia, suggesting the additional possibility that parallel mechanisms of psychosis may occur in schizophrenia and in a ketamine state, creating a potentially viable psychosis model for pathophysiology. This paper includes arguments in support of this human model's application. Several potential outcome measures that can be used to evaluate potentially novel antipsychotics are described. This model has the potential for identifying novel therapeutics because it does not primarily utilize the dopaminergic system. Further delineation of ketamine pharmacology in humans is pivotal to the eventual application of this ketamine model in drug development. [Neuropsychopharmacology 21:S158S169, 1999] (C) 1999 American College of Neuropsychopharmacology. Published by Elsevier Science Inc.
KEY WORDS: Animal model; Human model; NMDA; Glutamate; Ketamine; Phencyclidine

Because schizophrenia is an illness without known pathophysiology or etiology, no opportunity exists as yet to validate animal models of the illness. Schizophrenia models for antipsychotic drug development, especially if aimed at new strategies, are also limited. Despite this situation, we do have new drugs to treat schizophrenia and other psychoses, albeit all derived from the antidopaminergic model (Lahti et al. 1996).

From the Maryland Psychiatric Research Center, University of Maryland School of Medicine, Baltimore, MD.

Address correspondence to: Adrienne C. Lahti, M.D., Maryland Psychiatric Research Center, University of Maryland School of Medicine, P.O. Box 21247, Baltimore, MD 21228.

Received September 2, 1999; revised October 1, 1999; accepted October 4, 1999.
This has happened largely through identification of the mechanisms of conventional drug action and the design of new drugs based on the characteristics of past successes. Models for this standard approach begin with CNS-receptor affinity screening; desirable affinities include the $\mathrm{D}_{2}$-dopamine and the $5-\mathrm{HT}_{2}$-serotonin receptors, with consideration lately being given to the $5-\mathrm{HT}_{1 \mathrm{~A}}$, the $\alpha_{1}$, and the histamine ${ }_{1}$ receptors. $\mathrm{D}_{2}$-dopamine affinity is considered essential even though alternative approaches are being sought (Kehne et al. 1996; Lahti et al. 1998; Leysen et al. 1994; Schotte et al. 1996). Beyond receptor profiling, drug candidates are evaluated in animal behavioral and biochemical models that have predicted good clinical drug action in the past.

Despite its successes, several issues suggest that we need to move beyond this standard approach. Schizophrenia is a complex illness and may not represent a single disease entity (Andreasen et al. 1992; Carpenter 
and Buchanan 1994; Kirkpatrick and Buchanan 1990; Liddle et al. 1992). Moreover, it is an illness in which language is the medium for expressing mental symptoms, making animal models inadequate. At present, a family of animal models is used to characterize potential antipsychotic action (Bymaster et al. 1999). The concept of a "partial" model (i.e., one that might predict a segment of drug action, even a critical action, but is not sufficient by itself for full schizophrenia modeling) should be pursued based on our growing knowledge of schizophrenia.

Current data suggest that the symptoms of schizophrenia cluster together and express themselves as a group in individual patients. Positive symptoms (thought disorganization, hallucinations, delusions, paranoia), negative symptoms (thought paucity, psychosocial retardation, lack of motivation), and cognitive dysfunction (short-term memory impairment, attentional dysfunction, poor executive function) are the primary altered dimensions of cerebral function (Andreasen et al. 1992; Carpenter and Buchanan 1994; Liddle et al. 1992). Treatment for positive symptoms can be accomplished with antidopaminergic antipsychotics; however, the conventional drugs do not effectively treat negative manifestations or cognitive dysfunction. Even the new antipsychotics leave many aspects of the illness poorly treated. One idea being considered and tested is that a different drug treatment is needed for each domain of dysfunction in schizophrenia (Carpenter et al. 1993). Different aspects of schizophrenia might be mediated through and pharmacologically treated by different neurotransmitter or cerebral systems. In addition, the concept of a human model of schizophrenia deserves consideration, even given its inherent difficulties. Until now, disease models have been synonymous with animal models of schizophrenia despite the constraints of symptom expression. A human model would complement and extend the usual animal characterization, with the advantage of direct psychosis evaluation.

\section{EXISTING ANIMAL MODELS FOR PSYCHOSIS}

Evaluating animal models for face and construct validity is easier when the model is an exact replica of the human illness, a situation that can be obtained in diseases such as high blood pressure or stroke, in which etiology or pathophysiology can be mimicked. In psychiatric illnesses, however, the task is more difficult because of the obscure pathophysiology of these illnesses. In schizophrenia, the task is even more difficult because the primary symptoms are cognitive and are expressed through human language. To date, there is no practical human psychosis model. McKinney and Bunney (1969) proposed basic criteria for a model of a human brain disease that include the following: (1) the model is produced by a similar etiology as the illness; (2) the model resembles the illness in manifestations or symptomatology; (3) the underlying pathophysiology is similar to the human disorder; and (4) the responses to therapeutic treatments are similar. Several updates on these criteria have been proposed without critically changing these simple early concepts (Weiss and Kilts 1995). The more a model resembles the disease (in this case schizophrenia) along the parameters of these criteria, the more valid the model is likely to be.

The situation of inadequate animal models discourages many pharmaceutical teams focused on the brain from raising significant novel efforts in the antipsychotic area. Moreover, because the models are not "homologous" (i.e., do not mimic the human pathology), it is difficult to use them to study disease mechanisms. Despite these very significant limitations, it is clear that many drug development programs have been quite successful, even though they have been based on existing animal models (Beasley et al. 1997; Marder et al. 1993; Zimbroff et al. 1997). Although new approaches to drug development in schizophrenia are needed, because of only partial action of even the best antipsychotics, they are rarely pursued. Moreover, schizophrenia is observed around the world with relatively high frequency, and characteristically lasts a lifetime; hence, medical need is among the highest of all human illnesses. Where are we with animal models? Which models are the most reliable in predicting antipsychotic action? Which will predict novel therapeutic directions?

\section{Conditioned Avoidance Responding}

Conditioned avoidance responding is the classic behavioral antipsychotic drug screen. It is a part of virtually every drug development package in psychosis. Traditional and new antipsychotics (except clozapine) inhibit conditioned avoidance responding in rats at a dose that does not interfere with escape behavior (Cook and Catania 1964; Sanger 1985; Worms et al. 1983).

\section{Catalepsy}

The inability to correct an externally imposed body position is called catalepsy. Once used as a positive screening test for neuroleptics, catalepsy is now used as a "rule-out" screening test.

\section{Prepulse Inhibition (PPI)}

Schizophrenics and some of their family members lack the ability to have a weak sensory (e.g., auditory) stimulus, presented before a stronger stimulus (loud tone), modify the startle reaction to the loud tone (Braff and Geyer 1990). A homologue of this schizophrenia charac- 
teristic has been developed in the laboratory rat and fulfills many of the animal model criteria for human PPI reviewed above.

\section{Depolarization Blockade}

All antidopaminergic antipsychotics quiet spontaneous firing of midbrain dopamine cells with chronic drug treatment by producing depolarization blockade (Grace et al. 1997). Traditional antipsychotics generate this response in both A9 (motor) and A10 (limbic) dopamine cell body areas, but several of the new antipsychotics demonstrate this action only in the A10 neurons, thus putatively limiting their extrapyramidal symptoms (EPS).

\section{c-fos MRNA or Fos Protein Activation Pattern}

Delineation of the anatomic distribution of drug action may be informative about which cerebral behaviors a drug will effect. A restriction of drug action to the limbic cortex, especially to anterior cingulate regions without effects in the dorsal striatum, may be a model for a drug with antipsychotic but not parkinsonian action in the clinic (Robertson et al. 1994).

Several additional and even critical animal models are commonly used to further characterize antipsychotic drug action. Blockade of amphetamine-induced hypermotility but not stereotypy would suggest that a drug has activity at limbic but not motor regions of the brain (Arnt 1995). The action of an antipsychotic in the Paw Test (Ellenbroek and Cools 1988), the ability of the agent to inhibit hindlimb retraction more potently than forelimb retraction, has been empirically associated with the actions of newer (low EPS) drugs.

The failure of an antipsychotic to produce dystonias in the neuroleptic-sensitized nonhuman primate test suggests reduced potential for EPS in the clinic, a model with homologous and empirical support (Casey 1996). Social isolation in the animal, especially when induced by phencyclidine (PCP), is used theoretically to predict activity against negative symptoms (Sams-Dodd 1999). Hippocampal ablation (ventral) in the rat was developed as a homologous animal model to mimic the putative hippocampal pathology of schizophrenia and is associated with an increase in stimulated-dopamine release only after rat puberty (Weinberger 1995). Purposeless chewing movements with chronic antipsychotic treatment has been proposed as an animal model of tardive dyskinesia; hence, this model would be a negative screen in drug development (Tamminga et al. 1990; Waddington 1990). A hyperglutamatergic model of schizophrenic symptoms has been proposed based on perfusate analysis of rat prefrontal cortex showing activation of dopamine release following NMDA-antagonist administration and attenuation of this effect by pretreatment with an AMPA-receptor antagonist (Moghaddam et al.
1997) or a group II metabotropic glutamate receptor agonist (Moghaddam et al. 1998).

Chronic PCP administration in the nonhuman primate produces behaviors and neurochemical changes consistent with a schizophrenia-like process; evidence suggests that these PCP-induced changes are mediated through the medial and lateral frontal cortex (Jentsch and Roth 1999). These are the major modeling tools routinely used in animals to characterize drug action in humans for the therapeutic aim of antipsychotic action. No investigator would call these sufficient or even adequate, and all would be pessimistic about greatly improving these models in animals. This is because scientists need human response machinery to assess critical drug response features for schizophrenia. The human model of psychosis suggested here may extend pharmacologic characterization in evaluating new drug action.

\section{RATIONALE FOR THE NMDA-SENSITIVE GLUTAMATE ANTAGONISM MODEL}

PCP is the prototypic noncompetitive NMDA-receptor antagonist. It was studied for its mechanism of psychotomimetic action for many years after its initial behavioral characteristics were described (Domino and Luby 1981; Luby et al. 1959). PCP was always noted to have behavioral actions that in some ways approximated some of the signs and symptoms of schizophrenic psychosis (Javitt and Zukin 1991; Pearlson 1981). Unlike other psychotomimetic drugs (Angrist and Gershon 1970; Bell 1965; Griffith et al. 1972), PCP in a dose-dependent manner, can produce a range of classic psychotic phenomena in normal individuals, including hallucinations, delusions, and thought disorder. Early uncontrolled data suggested that PCP might exacerbate symptoms in schizophrenics, not just add a psychotomimetic action experience to their own symptoms (Luby et al. 1959). When Anis et al. (1983) reported that PCP and its congeners blocked the action of NMDA on ion flow through the NMDA-sensitive glutamate receptor in the brain, this action became the mechanism of interest in explaining behavioral actions of PCP. Soon, a PCP receptor was identified and characterized and, thereafter, its location within the NMDA-gated glutamate ionophore was further characterized (Zukin and Zukin 1979; Zukin et al. 1983). MK-801, its selective agonist, has made selectivity possible in the study of activation of this receptor site. Moreover, because PCP has a high affinity for its receptor, its actions mediated at this site are low-dose actions (Javitt and Zukin 1991), hence discriminable from its broad pharmacologic profile.

More recently, reports of psychotomimetic actions of other competitive NMDA antagonists suggest that any blockade of this ionophore will cause psychotomimetic side effects (Grotta et al. 1995; Kristensen et al. 1992). 
These observations have supported the idea that any drug or disease that reduces glutamatergic transmission at the NMDA site will be associated with psychosis. We have used the McKinney-Bunney "model" criteria to evaluate a potential ketamine model for psychosis in healthy humans (McKinney and Bunney 1969). The first model criterion, etiology, is not helpful because there is no known mechanism for either schizophrenia or ketamine-induced psychosis. The second criterion, symptomatology, is applicable; data support a ketamine interview in humans as a model of psychosis for the reasons elaborated above and described more fully below. Whether a ketamine preparation has a biochemistry that matches psychosis is an unanswered question because we do not know the pathophysiology of psychosis. The third criterion, whether the pathophysiology of the model matches the human condition, requires data that we and others are in the process of collecting. Haloperidol blocks endogenous psychosis but does not affect ketamine-induced psychosis (Lahti et al. 1995b); clozapine seems to block at least some of the psychotomimetic actions of ketamine in humans (Malhotra et al. 1997a). Moreover, several agents, when tested in humans, block some of the ketamine-induced symptoms in normal individuals [e.g., lamotragine (Anand et al. 1999) and guanabenz (Newcomer et al. 1999b)]. Thus, acute ketamine blockade may be a partial model of psychosis for positive symptoms and perhaps cognitive dysfunction and contribute to identifying an additional aspect of antipsychotic action over conventional drugs. The fact that haloperidol does not block the ketamine psychotomimetic action could mean that ketamine is acting to produce psychosis in humans closer to its core pathology than is affected by dopamine. Clearly, further work is needed in characterizing ketamine pharmacology in humans.

We propose that the ketamine model, described in detail below, be considered for a "partial" human model for psychosis. The ketamine model suggests novel and superior therapeutic characteristics of a potential new antipsychotic and can be used along with the usual laboratory receptor affinity and traditional animal model screens.

\section{DEVELOPMENT OF A HUMAN MODEL OF PSYCHOSIS WITH KETAMINE}

Background work on this preparation began in our laboratory with a dose-response study of the action of ketamine inducing psychotic symptomatology in healthy humans (Lahti et al. 1997). This study was also carried out in schizophrenic volunteers. All participants were informed about all aspects of the study, including the probability that they would experience psychotic symp- toms. Symptom experiences from previous participants were shared with volunteers participating in the study. After the informational process, all potential volunteers were evaluated to ensure their full understanding of the experiment. Whenever available, family members of the patient volunteers were involved in the informed consent process. The ketamine procedure was carried out in a quiet room with reduced stimulation and in a relaxed setting. Each volunteer underwent four sessions, one with each dose of $0.1,0.3$, or $0.5 \mathrm{mg} / \mathrm{kg}$ ketamine, or placebo given in random order and in a double-blind manner. Ketamine and placebo were administered intravenously over 60 seconds. Symptoms were rated at baseline, and at 20,90, and 180 minutes after drug; patients were debriefed 24 hours later. The Brief Psychiatric Rating Scale (BPRS) (Overall and Gorhain 1962) and the Psychosis Change Scale (PCS) (Tamminga and Schaffer 1979) were used to rate responses. Blood oxygen saturation and usual vital signs were assessed regularly.

Ketamine produced a dose-dependent increase in psychotic symptoms in healthy human volunteers. The magnitude of the responses was similar in healthy and schizophrenic volunteers, differing only in that schizophrenics started with a higher psychosis at baseline. The healthy volunteers had an increase in both positive and negative symptoms (Figure 1), whereas the schizophrenic persons had an increase in only the positive symptoms. Normal volunteers experienced illusions and distortions in the visual, auditory, and somaesthetic domains; schizophrenic patients reported similar phenomenon as well as frank hallucinations, both unformed (e.g., popping sounds) and formed (e.g., voices), and delusional beliefs. Both groups experienced thought disorganization. These symptoms lasted from 20 to 40 minutes, with an average of $19 \pm 6.4 \mathrm{~min}-$ utes in healthy volunteers and $31.8 \pm 21.2$ minutes in schizophrenic volunteers.

Perhaps the most striking feature of the response to ketamine in the patient group was that approximately $75 \%$ of patients experienced symptoms reminiscent of their acute symptoms both in content and extent. Whether their primary symptoms were a particular paranoid delusion or a set of hallucinations on a theme, it was those symptoms that were mildly stimulated in the patient group. Schizophrenic volunteers were tested both on and off haloperidol $(n=6)$; ketamine demonstrated the same psychotomimetic action under both conditions, with the off-haloperidol volunteers starting from a higher psychosis baseline (Figure 2).

To understand the areas of the brain involved in this behavioral response, we evaluated regional cerebral blood flow (rCBF) in both volunteer populations after a $0.3-\mathrm{mg} / \mathrm{kg}$ dose of ketamine. The $0.3-\mathrm{mg} / \mathrm{kg}$ dose was selected because it was sufficient to give a clear signal in both populations with only mild psychosis. rCBF 

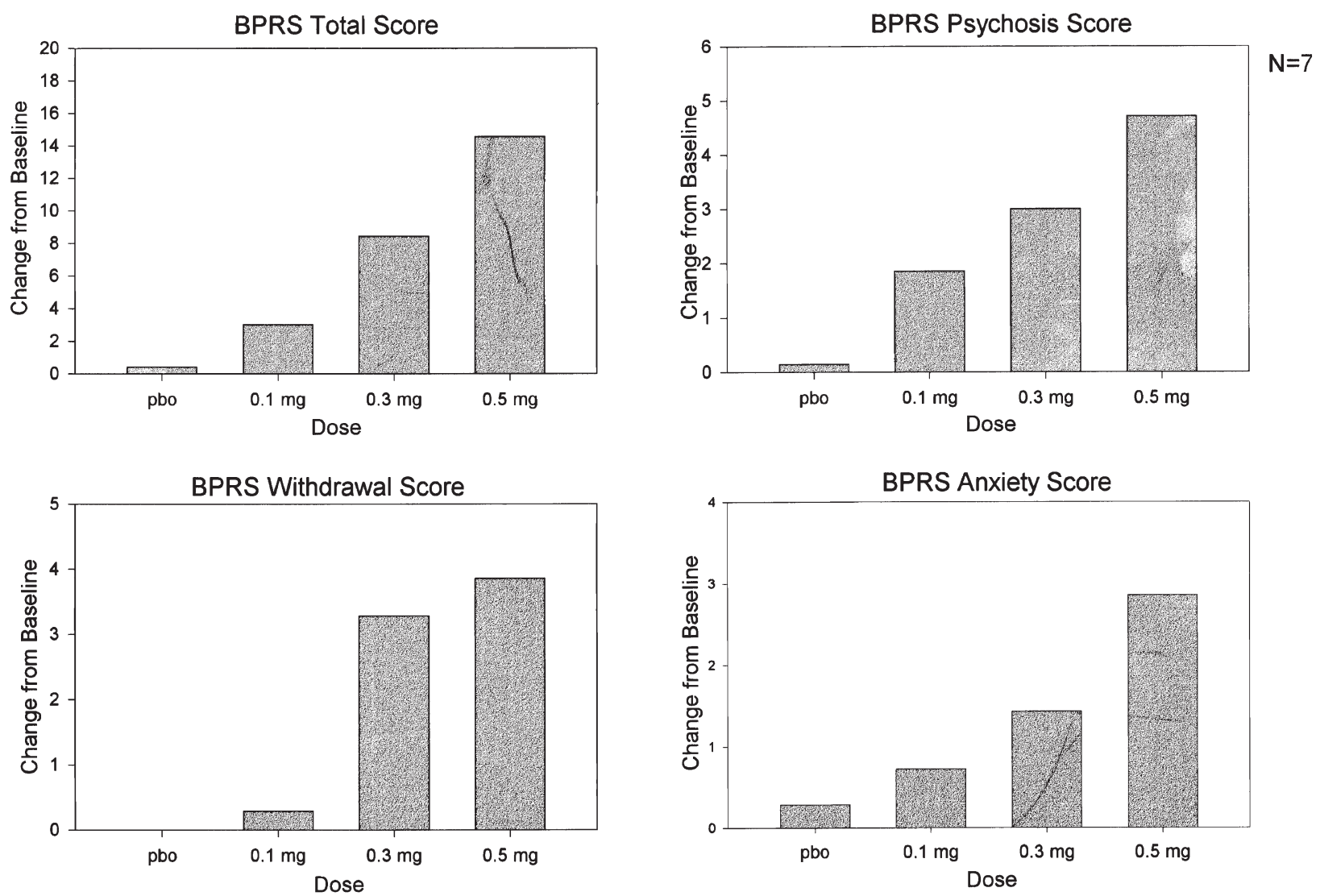

Figure 1. Mental changes 20 minutes after ketamine injection in normal volunteers $(n=7)$ after three doses of ketamine $(0.1,0.3$, and $0.5 \mathrm{mg} / \mathrm{kg}$ ) and placebo (pbo). There was a dose-related increase in the BPRS Psychosis score for all three ketamine doses and BPRS Withdrawal score for the two higher ketamine doses. The BPRS Anxiety score was significantly increased only for the higher ketamine dose $(0.5 \mathrm{mg} / \mathrm{kg})$.

scans were collected using PET with $\mathrm{H}_{2}{ }^{15} \mathrm{O}$. Three scans were collected at baseline and repeated at 10-minute intervals after ketamine administration for 60 minutes. Scan data were analyzed using SPM96 (Friston et al. 1994).

The data presented here represent the subtraction of the average baseline scan from an average 6- to 16minute scan. Both healthy and schizophrenic volunteers showed the same distributions and magnitudes of activation/inhibition; therefore, the data here are pooled. Ketamine increased rCBF most prominently in the anterior cingulate cortex, with the activation extending into the medial frontal areas bilaterally (Figure 3). Activation was also significant in the right inferior frontal cortex in a smaller area. $\mathrm{rCBF}$ was inhibited in cerebellum, throughout the cerebellar cortex bilaterally. Each cerebral area of activation and inhibition demonstrated its own time course of response with a distinctive dynamic pattern (Figure 4). In two cerebral regions, the anterior cingulate gyrus and the inferior frontal gyrus (Figure 5), a significant linear correlation emerged between the change in psychosis and $\mathrm{rCBF}$ activation in response to ketamine. Several areas of activation/inhi- bition demonstrated a dose-sensitive rCBF response across $0.1-, 0.2-$, and $0.3-\mathrm{mg} / \mathrm{kg}$ dose curve, including the anterior cingulate, premotor, and medial prefrontal cortex.

Evidence suggests that ketamine produces its psychotomimetic action in humans through blockade of the NMDA-sensitive glutamate ionotrophic receptor. The effective doses causing the psychotomimetic response are very low, and ketamine as well as PCP has a high affinity for the NMDA receptor (Javitt and Zukin 1991). Moreover, several competitive antagonists of the NMDA receptor are associated with a similar psychotomimetic action. These NMDA antagonists have been tested in humans under experimental conditions because of their potential blockade of neurodegeneration after stroke and seizures. MK-801 [(+)-5-methyl-10,11dihydro-5H-dibenzo $(\mathrm{a}, \mathrm{d})$ cyclohepten-5,10-imine maleate], CGS 19755 [cis-4-[phosphonomethyl]-2-piperidine carboxylic acid] (Grotta et al. 1995), and CPP [3-(2-carboxypiperazin-4-yl)propyl-l-phosphonic acid] (Kristensen et al. 1992) all induced psychotomimetic symptoms in humans.

Full pharmacologic characterization of the ketamine- 


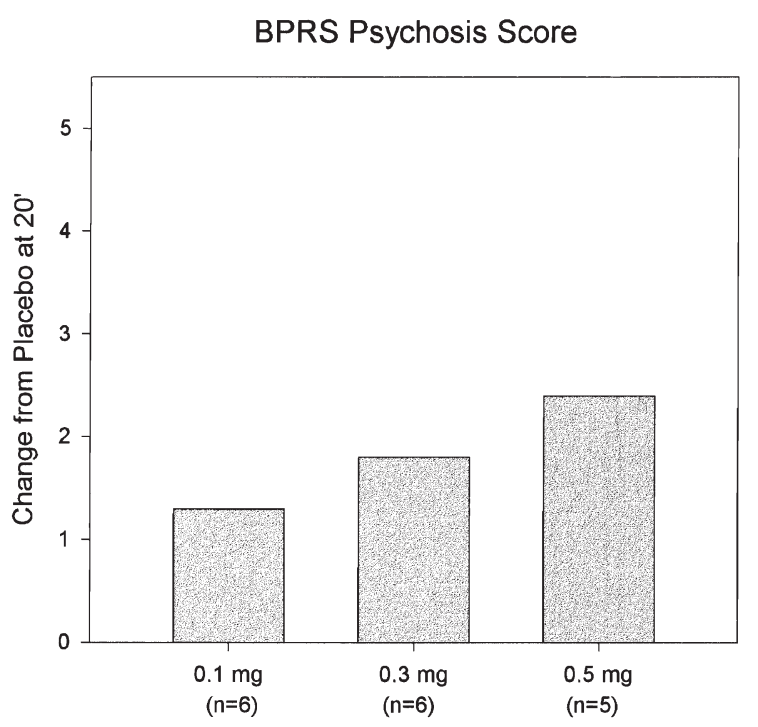

OFF Haloperidol

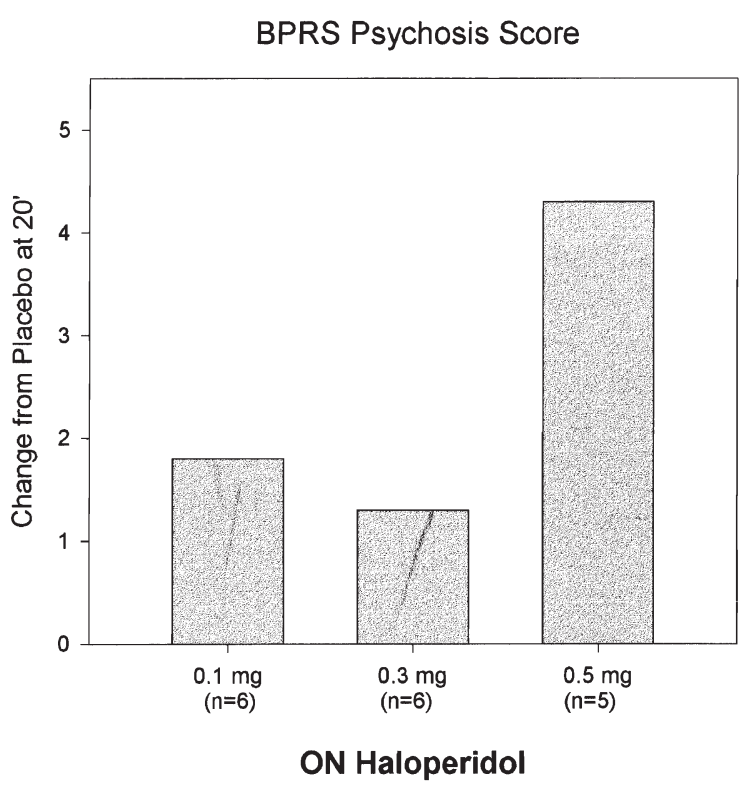

Figure 2. Changes in BPRS psychosis score 20 minutes after three doses of ketamine and placebo in schizophrenic patients $(n=6)$ who received challenges both on (ON haloperidol) and off (OFF haloperidol) haloperidol. Neither the increase in BPRS Psychosis score at 20 minutes nor the BPRS Psychosis score at baseline was significantly different between conditions, indicating that haloperidol did not block ketamine-induced psychosis.

induced behaviors and rCBF changes will be critical to testing the extent of its further application. We have begun studying the blockade of ketamine-induced behavioral outcomes with a conventional antipsychotic (haloperidol) and a newer antipsychotic (olanzapine). Healthy and schizophrenic volunteers respond similarly, so healthy subjects are routinely selected. Halo- peridol does not block ketamine-induced behaviors at a dose of $10 \mathrm{mg}$. Olanzapine evaluations are still incomplete; however, preliminary data suggest that low doses (5 mg) of olanzapine do not block ketamine-induced symptoms of psychosis (Lahti et al. 1999). The experiment is being extended to higher doses of olanzapine based on our knowledge that additional neurochemical

\section{Stimulation}

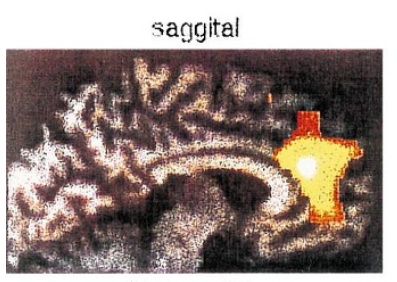

transverse

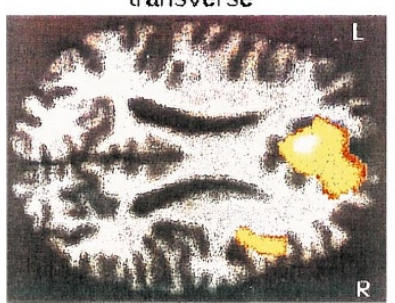

coronal
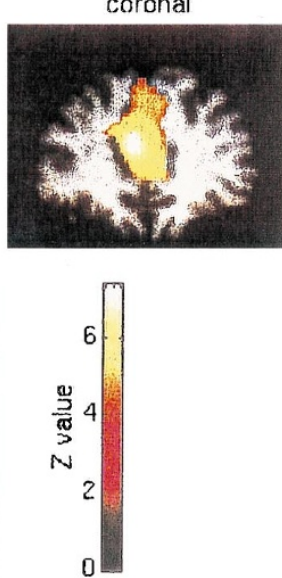

Suppression

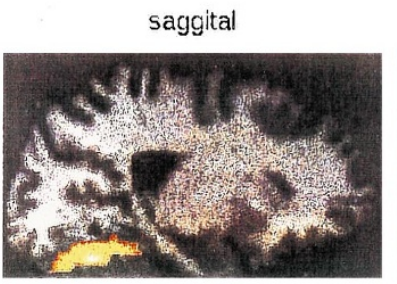

transverse

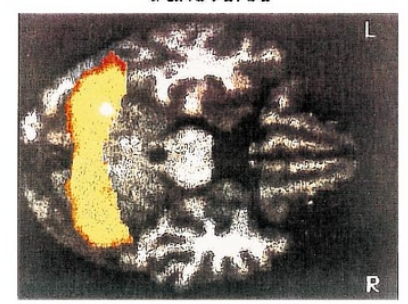

coronal
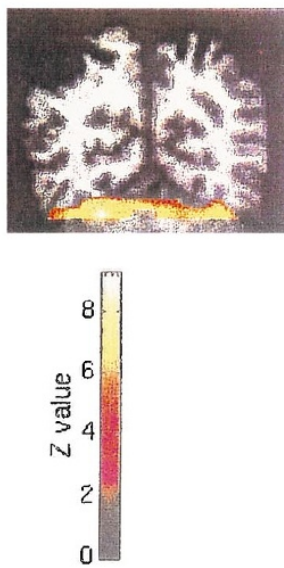

Figure 3. Transverse, sagittal, and coronal statistical parametric maps derived from ${ }^{15} \mathrm{O}-$ labeled water PET scans in normal and schizophrenic volunteers $(n=17)$. These maps indicate the difference in rCBF obtained before and 6 to 16 minutes (average of two scans) after ketamine bolus injection $(0.3 \mathrm{mg} / \mathrm{kg})$. Ketamine-induced rCBF stimulation is seen in anterior cingulate (extending to medial frontal areas bilaterally) and right inferior frontal cortical area, and rCBF suppression is seen throughout the cerebellar cortex bilaterally. 


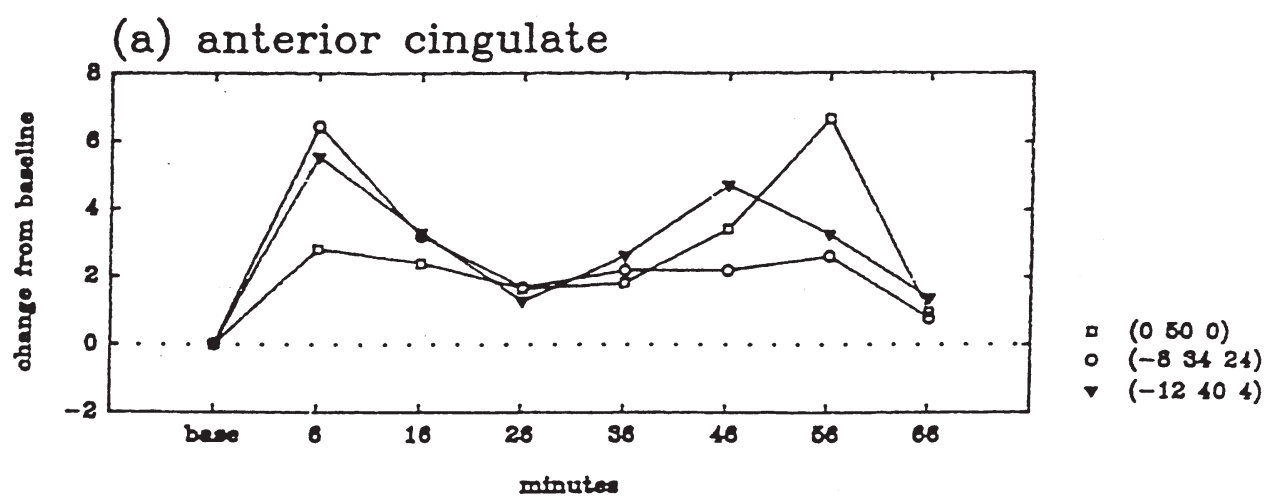

(b) inferior frontal gyrus (R)

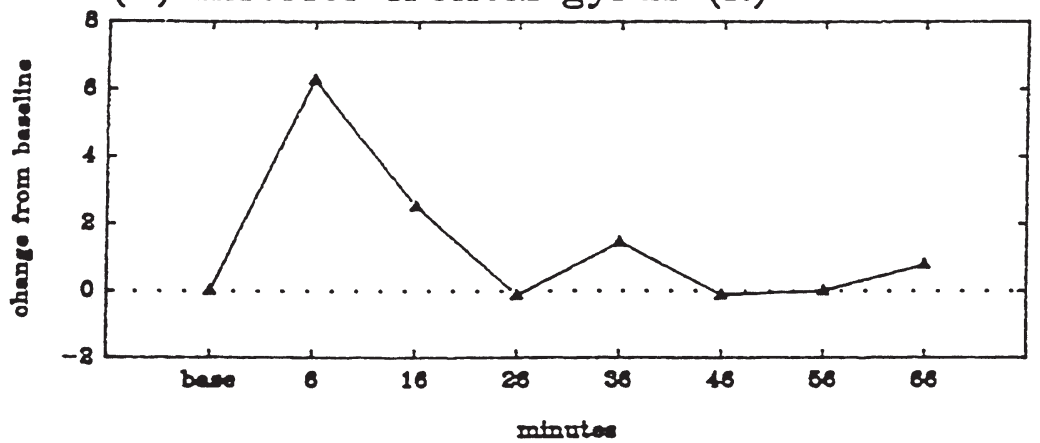

\section{(c) cerebellum}

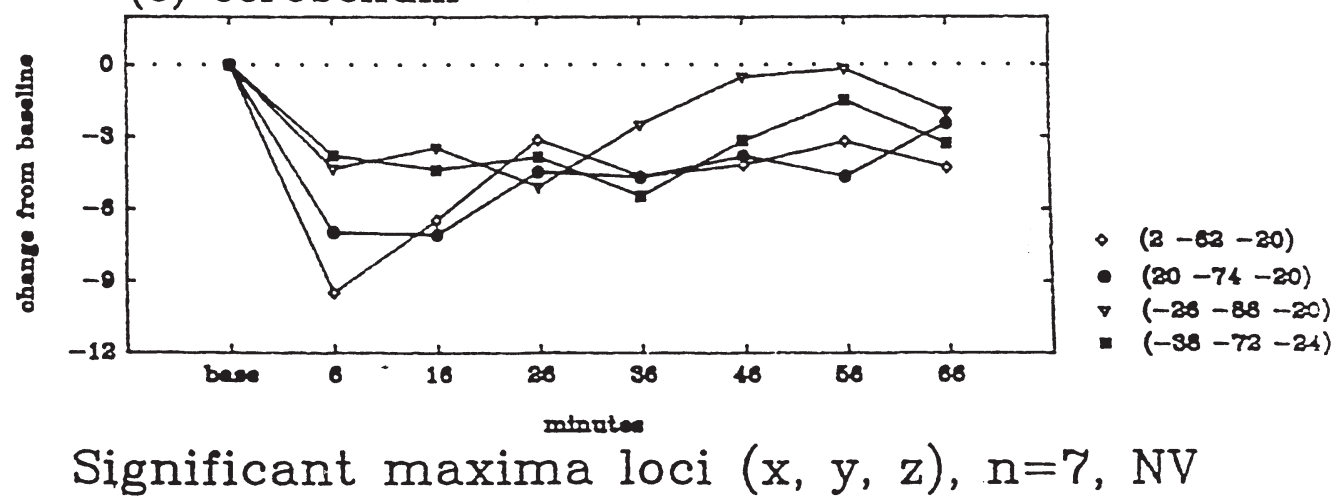

Figure 4. Regional change in CBF over the first 66 minutes following $0.3 \mathrm{mg} / \mathrm{kg}$ bolus ketamine in normal volunteers $(n=$ $7)$. Baseline rCBF scans and seven scans at 10-minute intervals after drug were obtained. Group average images were constructed at each time point, the maxima of any significant cluster was grown to a $6 \times 6 \times 12$ voxel sample volume; an average adjusted rCBF was calculated and plotted for each time point. rCBF in anterior cingulate ( 3 maxima) showed a biphasic pattern with early and late flow increases. The inferior frontal area showed a single activation between 6 and 16 minutes. All maxima (4) showed relative flow reduction monophasically in cerebellum.

actions should appear at higher doses (Kroeze and Roth 1998).

Data from other laboratories expand these observations. Several investigators have evaluated the effect of ketamine in normal (Krystal et al. 1994; Malhotra et al. 1996) and schizophrenic volunteers (Malhotra et al. 1997b). Despite differences in methods of ketamine administration (bolus vs. slow infusion), there is a consensus across laboratories that ketamine produces a close symptom representation of the positive symptoms of schizophrenia in healthy humans. Malhotra et al. (1997b) reported a high degree of similarity between ketamine-induced psychosis and a patient's own psychotic symptoms. Various studies have reported physiologic/mental abnormalities produced in healthy humans by ketamine that mimic changes found in schizophrenia, including changes in several measures of cognition (Harborne et al. 1996; Krystal et al. 1994; LaPorte et al. 1996; Malhotra et al. 1996; Newcomer et al. 1999a), eye tracking (Radant et al. 1998; Weiler et al. 

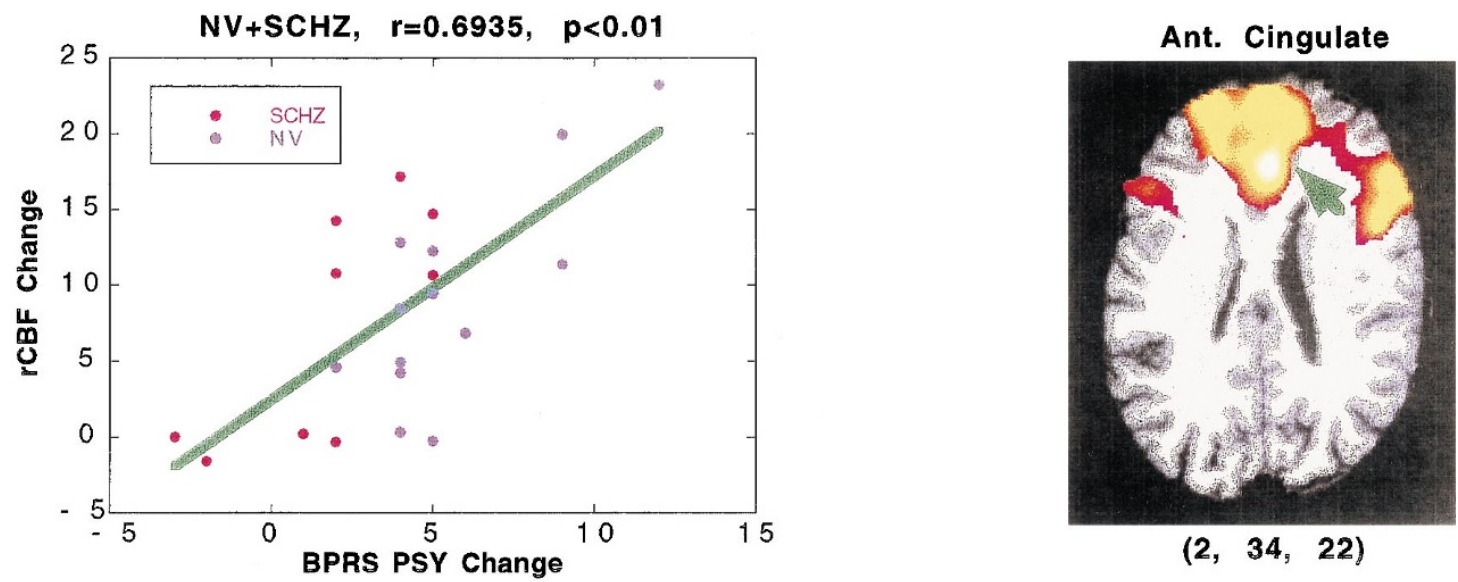

$(2,34,22)$
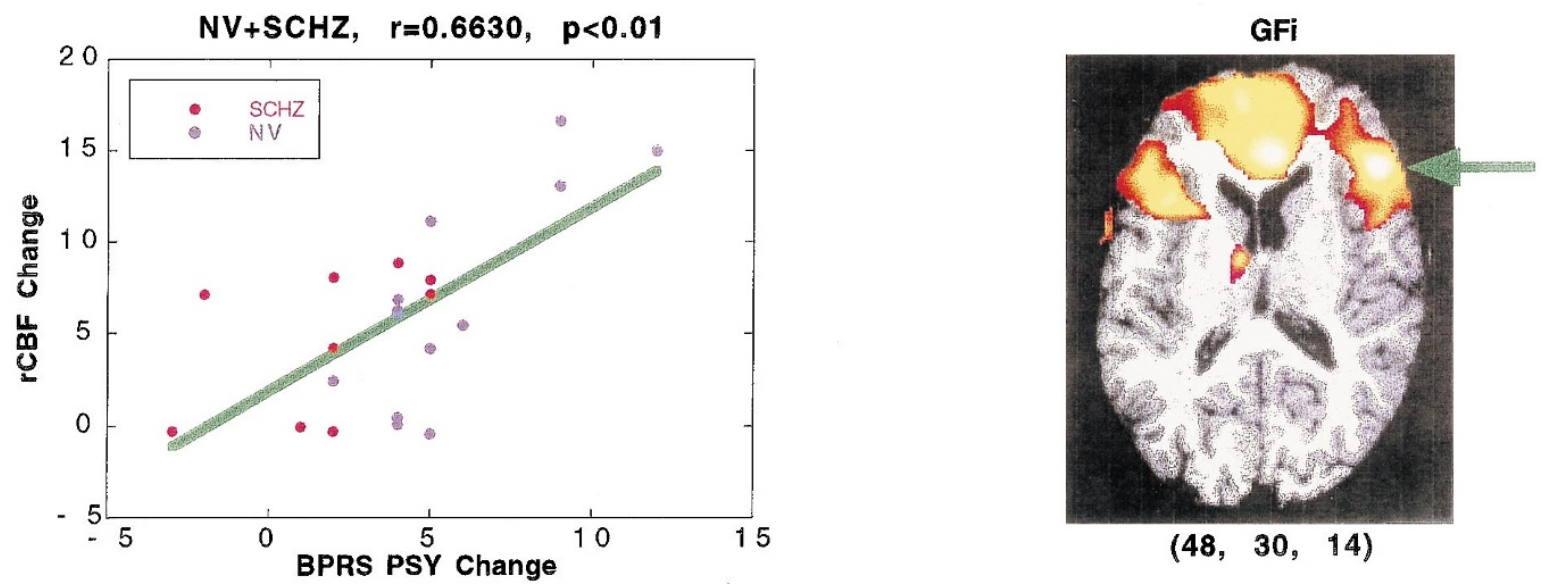

Figure 5. Statistical Parametric Mapping (SPM96) was used to generate pixel by pixel linear regression correlation between BPRS Psychosis change score (obtained prior to PET procedure and 20 minutes postdose) against rCBF changes (subtraction of baseline scans and average of 6 to 16 minute scans) in normal and schizophrenic volunteers $(n=22)$. Both the anterior cingulate and inferior frontal gyrus demonstrate a significant linear correlation between the ketamine-induced change in psychosis and $\mathrm{rCBF}$ activation.

1997), and PPI (Duncan et al. 1997). Although we need to evaluate whether the mechanisms of these ketamineinduced impairments in healthy humans are the same mechanisms operative in schizophrenia, these studies may provide a way to associate glutamatergic abnormalities with the signs and symptoms of schizophrenia.

Imaging studies with ketamine have also been performed in other laboratories to describe brain-activation patterns following ketamine administration in schizophrenic (Lahti et al. 1995a) and normal volunteers (Breier et al. 1997; Vollenweider et al. 1997) and to evaluate in vivo glutamate-dopamine interactions (Breier et al. 1998). Vollenweider et al. (1997), using PET with $\left[{ }^{18} \mathrm{~F}\right]$ fluorodeoxyglucose (FDG), reported frontal cortex and cingulate cortex metabolic activation with ketamine in normal volunteers. Also using PET/FDG, Breier et al. (1998) reported frontal activation in normal volunteers in response to ketamine. In a displacement PET study with $\left[{ }^{11} \mathrm{C}\right]$ raclopride, Breier (1997) reported that ketamine decreased specific $\mathrm{D}_{2}$-dopamine binding in the basal ganglia of healthy volunteers, indicating that at least in some CNS regions, dopamine release is produced by ketamine administration. It is not known whether this interaction is related to the induction of symptoms.

Pharmacological blockade of ketamine is also now being evaluated in different laboratories using various agents. Clozapine seems to mildly but significantly blunt ketamine-induced psychosis in schizophrenic volunteers (Malhotra et al. 1997a). Moreover, clozapine seems to reduce the ketamine-induced rCBF change in anterior cingulate cortex (Vollenweider and Leenders 1999). Lorazepam does not block ketamine-induced psychotic symptoms but, it significantly blunted anxiety ratings associated with ketamine administration in normal volunteers (Krystal et al. 1998). Preliminary data indicate that other compounds, including the antiepileptic lamotrigine, reduce ketamine-induced positive and negative symptoms in normal volunteers, hypothetically, through an ability to inhibit presynaptic release of 
glutamate (Anand et al. 1999). The $\alpha_{2}$ agonist guanabenz, is also being investigated in normal volunteers (Newcomer et al. 1999b).

This human ketamine model and its homologue in the rat with PCP and immediate early gene (IEG) activation have already suggested cerebral areas potentially important to psychosis. Analysis of the ketamine activation/inhibition patterns and the regions where rCBF and ketamine-induced behaviors correlate indicates CNS regions mediating specific ketamine effects. The localizing data from this ketamine model have already been valuable within our own laboratory in directing regional postmortem studies in healthy and schizophrenic postmortem tissue (Gao et al. 1999). Moreover, this model might be useful in identifying those new antipsychotic drugs that might confer special, additional, or novel antipsychotic benefits beyond the action of conventional antipsychotics.

\section{A HOMOLOGOUS PCP MODEL IN THE RAT WITH ACTIVATIONAL ANALYSIS}

The ketamine model in healthy humans with behavioral and rCBF analysis has a homologous animal preparation using PCP with behavioral, IEG, or 2-deoxyglucose (2DG) analysis in the laboratory rat. Examination of the distribution of glucose utilization (Duncan et al. 1998; Tamminga et al. 1987; Weissman et al. 1987) or IEG (Gao et al. 1998) activation/inhibition produced by PCP parallels largely the distribution of ketamine-induced rCBF changes in humans. While not taking the place of a healthy human model, PCP-induced regional biochemical changes in the rat are both more available for full experimental examination and a more efficient initial screen for new antipsychotic candidates. Moreover, similar to the proposed human model, this animal model has the advantage of potentially uncovering novel mechanisms of antipsychotic activity because of its neurochemical action at the NMDA-sensitive ionophore. This homologous animal technique is especially valuable when used together with the ketamine model in humans.

Other actions of PCP in laboratory animals are already used for psychosis modeling [e.g., in PPI studies (Swerdlow et al. 1998)], in primate social behavior studies (Corbett et al. 1995), and in histologic studies (Farber et al. 1998).

We are currently using this PCP preparation to screen conventional, new, and potential antipsychotics to characterize their actions on the PCP-induced IEG changes. Our preliminary data indicate that d-cycloserine fully inhibits the actions of PCP in all brain areas. Haloperidol inhibits PCP effects on IEGs in some areas, whereas olanzapine blocks PCP-induced IEG changes in most brain areas. The primary advantage of this model in identifying novel nondopaminergic antipsychotics will occur with screens of glutamatergic drugs in the animal model first and then, if positive, in the human model. Because the actions of these PCP antagonists differ regionally and differ in their human actions, an obvious link may establish the relationship between drug action and a region with a PCP-induced action more closely.

\section{CONCLUSIONS}

The ketamine model in healthy human volunteers and the PCP model in rats can be used to study the pathophysiology of psychosis and as a potential screen for superior antipsychotic drug action. This model can be extended to the schizophrenic volunteer if a question arises that can only be addressed in association with the illness. Ketamine is highly valuable as a human probe for the glutamate system, perhaps the only one currently available. Because it produces a mild psychotomimetic response in both healthy and schizophrenic volunteers, ketamine needs to be applied in the context of ethical scrutiny: informed consent, family participation, immediate and extended follow-up, and close institutional review. In addition, this probe cannot be used in humans frivolously, in situations where scientific merit is lacking, or when the question could be answered in a simpler way. Attention to risk/benefit aspects of a study is more critical here than in benign human studies. In this context of heightened awareness, ketamine use in the study and treatment of schizophrenia deserves further evaluation.

\section{ACKNOWLEDGMENT}

Supported by an unrestricted educational grant from Hoechst Marion Roussel.

\section{REFERENCES}

Anand A, Berman R, Oren D, Chamey DS, Krystal JH (1999): Attenuation of NMDA antagonist effects in healthy humans by larnotrigine, a drug that reduces glutamate release. Schizophr Res 36:305

Andreasen NC, Rezai K, Alliger RJ, Swayze VW, Flaum M, Kirchner P, Cohen G, O'Leary DS (1992): Hypofrontality in neuroleptic-naive patients and in patients with chronic schizophrenia. Arch Gen Psychiatry 49:943-958

Angrist BM, Gershon S (1970): The phenomenology of experimentally induced amphetamine psychosis: Preliminary observations. Biol Psychiatry 2:95-107

Anis NA, Berry SC, Burton NR, Lodge D (1983): The dissociative anesthetics ketamine and phencyclidine selec- 
tively reduce excitation of central mammalian neurons by N-methyl-D-aspartate. Br J Pharmacol 79:5654-5675

Arnt J (1995): Differential effects of classical and newer antipsychotics on the hypermotility induced by two dose levels of d-amphetamine. Eur J Pharmacol 283:5562

Beasley CM Jr, Tollefson G, Tran P, Satterlee W, Sanger G, Hamilton $S$ (1997): Olanzapine versus placebo and haloperidol: Acute phase results of the North American double-blind olanzapine trial. Neuropsychopharmacology 14:111-123

Bell DS (1965): A comparison of amphetamine psychosis and schizophrenia. Br J Psychiatry 3:701-707

Braff DL, Geyer MA (1990): Sensorimotor gating and schizophrenia: Human and animal model studies. Arch Gen Psychiatry 47:181-188

Breier A, Adler CM, Weisenfeld N, Su TP, Elman I, Picken L, Malhotra AK, Pickar D (1998): Effects of NMDA antagonism on striatal dopamine release in healthy subjects: Application of a novel PET approach. Synapse 29:142147

Breier A, Malhotra AK, Pinals DA, Weisenfeld NI, Pickar D (1997): Association of ketamine-induced psychosis with focal activation of the prefrontal cortex in healthy volunteers. Am J Psychiatry 154:805-811

Bymaster FP, Moore NA, Nakazawa T (1999): Review of the preclinical pharmacology of olanzapine: A MARTA class antipsychotic. Psychopharmacology 2:885-911

Carpenter WT Jr, Buchanan RW (1994): Schizophrenia. N Engl J Med 330:681-690

Carpenter WT Jr, Buchanan RW, Kirkpatrick B, Tamminga CA, Wood F (1993): Strong inference, theory testing, and the neuroanatomy of schizophrenia. Arch Gen Psychiatry 50:825-831

Casey DE (1996): Behavioral effects of sertindole, risperidone, clozapine and haloperidol in Cebus monkeys. Psychopharmacology 124:134-140

Cook L, Catania AC (1964): Effects of drugs on avoidance and escape behavior. Fed Proc 23:818-835

Corbett R, Camacho F, Woods AT, Kennan LL, Fishkin RJ, Brooks K, Dunn RW (1995): Antipsychotic agents antagonize non-competitive N-methyl-D-aspartate antagonist-induced behaviors. Psychopharmacology 120:67-74

Domino EF, Luby E (1981): Abnormal mental states induced by phencyclidine as a model of schizophrenia. In Domino EF (ed), PCP (Phencyclidine): Historical and Current Perspectives. Ann Arbor, MI, NPP Books, pp 401413

Duncan E, Madonick SH, Angrist BM, Bartlett E, Parwani A, Rotrosen JP (1997): N-methyl-d- aspartate modulation of prepulse inhibition. Am Psychiatric Assoc Annual Meeting

Duncan GE, Leipzig JN, Mailman RB, Lieberman JA (1998): Differential effects of clozapine and haloperidol on ketamine-induced brain metabolic activation. Brain Res 812:65-75

Ellenbroek B, Cools AR (1988): The Paw test: An animal model for neuroleptic drugs which fulfills the criteria for pharmacological isomorphism. Life Sci 42:1205-1213

Farber NB, Hanslick J, Kirby C, McWilliams L, Olney JW
(1998): Serotonergic agents that activate 5HT2A receptors prevent NMDA antagonist neurotoxicity. Neuropsychopharmacology 18:57-62

Friston KJ, Worsley KJ, Frackowiak RSJ, Mazziotta JC, Evans AC (1994): Assessing the significance of focal activations using their spatial extent. Hum Brain Mapping $1: 210-220$

Gao XM, Hashimoto T, Tamminga CA (1998): Phencyclidine (PCP) and dizocilpine (MK801) exert time-dependent effects on the expression of immediate early genes in rat brain. Synapse 29:14-28

Gao XM, Sakai K, Roberts RC, Conley RR, Dean B, Tamminga CA (1999): Ionotropic glutamate receptors and NMDA subunit expression in subregions of human hippocampus: Effects of schizophrenia. Am J Psychiatry, in press

Grace AA, Bunney BS, Moore H, Todd CL (1997): Dopamine-cell depolarization block as a model for the therapeutic actions of antipsychotic drugs. TINS 20:31-37

Griffith JD, Cavanaugh J, Held J (1972): Dextroamphetamine: Evaluation of psychomimetic properties in man. Arch Gen Psychiatry 26:97-100

Grotta J, Clark W, Coull B, Pettigrew LC, Mackay B, Goldstein LB, Meissner I, Murphy D, LaRue L (1995): Safety and tolerability of the glutamate antagonist CGS 19755 (Selfotel) in patients with acute ischemic stroke. Results of a phase IIa randomized trial. Stroke 26:602-605

Harborne GC, Watson FL, Healy DT, Groves L (1996): The effects of sub-anaesthetic doses of ketamine on memory, cognitive performance and subjective experience in healthy volunteers. J Psychopharmacol 10:134-140

Javitt DC, Zukin SR (1991): Recent advances in the phencyclidine model of schizophrenia. Am J Psychiatry 148:1301-1308

Jentsch JID, Roth RH (1999): The neuropsychopharmacology of phencyclidine: From NMDA receptor hypofunction to the dopamine hypothesis of schizophrenia. Neuropsychopharmacology 20:201-225

Kehne JH, Baron BM, Carr AA, Chaney SF, Elands J, Feldman DJ, Frank RA, VanGiersbergen PLM, McCloskey TC, Johnson MP, McCarty DR, Poirot M, Senyah Y, Siegel BW, Widmaier C (1996): Preclinical characterization of the potential of the putative atypical antipsychotic MDL 100,907 as a potent 5-HT2A antagonist with a favorable CNS safety profile. J Pharmacol Exp Ther 277:968-981

Kirkpatrick B, Buchanan R (1990): The neural basis of the deficit syndrome of schizophrenia. J Nerv Ment Dis 178:545-555

Kristensen JD, Svensson B, Gordh T Jr (1992): The NMDAreceptor antagonist $\mathrm{CPP}$ abolishes neurogenic 'wind-up pain' after intrathecal administration in humans. Pain 51:249-253

Kroeze WK, Roth BL (1998): The molecular biology of serotonin receptors: Therapeutic implications for the interface of mood and psychosis. Biol Psychiatry 44:11281142

Krystal JH, Karper LP, Bennett A, D'Souza DC, AbiDargham A, Morrissey K, Abi-Saab D, Bremmer JD, Bowers MB, Suckow RF, Stetson P, Heninger GR, Charney DS (1998): Interactive effects of subanesthetic 
ketamine and subhypnotic lorazepam in humans. Psychopharmacology 135:213-229

Krystal JH, Karper LP, Seibyl JP, Freeman GK, Delaney R, Bremmer JD, Heninger GR, Bowers IMB, Charney DS (1994): Subanesthetic effects of the noncompetitive NMDA antagonist, ketamine, in humans. Arch Gen Psychiatry 51:199-214

Lahti AC, Holcomb HH, Medoff DR, Tamminga CA (1995a): Ketamine activates psychosis and alters limbic blood flow in schizophrenia. Neuroreport 6:869-872

Lahti AC, Koffel B, LaPorte D, Tamminga CA (1995b): Subanesthetic doses of ketamine stimulate psychosis in schizophrenia. Neuropsychopharmacology 13:9-19

Lahti AC, Lahti RA, Tamminga CA (1996): New neurolepties and experimental antipsychotics: Future roles. In Breier A (ed), The New Pharmacotherapy of Schizophrenia. Washington, DC, American Psychiatric Press, pp 57-87

Lahti AC, Holcomb HH, Weiler MA, Corey PK, Zhao M, Medoff D, Tamminga CA (1997): Effects of ketamine on behavior and rCBF in schizophrenia and normal individuals. Biol Psychiatry 41:165-169

Lahti AC, Weiler MA, Corey PK, Lahti RA, Carlsson A, Tamminga CA (1998): Antipsychotic properties of the partial dopamine agonist (-)-3-(3-Hydroxyphenyl)-N-nPropylpiperidine (Preclamol) in schizophrenia. Biol Psychiatry 43:2-11

Lahti AC, Weiler MA, Parwani A, Holcomb HH, Michaelidis T, Warfel D, Tamminga CA (1999): Blockade of ketamine-induced psychosis with olanzapine. Schizophr Res 36:310

LaPorte DJ, Lahti AC, Koffel B, Tamminga CA (1996): Absence of ketamine effects on memory and other cognitive functions in schizophrenic patients. J Psychiatr Res 30:321-330

Leysen JE, Janssen PM, Megens AA, Schotte A (1994): Risperidone: A novel antipsychotic with balanced serotonin-dopamine antagonism, receptor occupancy profile, and pharmacologic activity. J Clin Psychiatry 55:5-12

Liddle PF, Friston KJ, Frith CD, Hirsch SR, Jones T, Frackowiak RS (1992): Patterns of cerebral blood flow in schizophrenia. Br J Psychiatry 160:179-186

Luby ED, Cohen BD, Rosenbaum G, Gottlieb JS, Kelley R (1959): Study of a new schizophrenomimetic drug: serenyl. Arch Neurol Psychiatry 71:363-369

Malhotra AK, Adler CM, Kennison SD, Elman 1, Pickar D, Breier A (1997a): Clozapine blunts N-methyl-D-Aspartate antagonist-induced psychosis: A study with ketamine. Biol Psychiatry 42:664-668

Malhotra AK, Pinals DA, Adler CM, Elman I, Clifton A, Pickar D, Breier A (1997b): Ketamine-free schizophrenics. Neuropsychopharmacology 17:141-150

Malhotra AK, Pinals DA, Weingartner H, Sirocco K, Missar CD, Pickar D, Breier A (1996): NMDA receptor function and human cognition: The effects of ketamine in healthy volunteers. Neuropsychopharmacology 14:301307

Marder SR, Chouinard G, Jones B, Remington G, Bloom D, Addington D, MacEwan GW, Labelle A, Beauclair L, Arnott W (1993): Risperidone: Clinical development: North American results. A Canadian multicenter pla- cebo-controlled study of fixed doses of risperidone and haloperidol in the treatment of chronic schizophrenic patients. Clin Neuropharmacol 13:25-40

McKinney WT, Bunney WE Jr (1969): Animal model of depression. I. Review of evidence: Implications for research. Arch Gen Psychiatry 21:240-248

Moghaddam B, Adams BW (1998): Reversal of phencyclidine effects by a group II metabotropic glutamate receptor agonist in rats. Science 281:1349-1352

Moghaddam B, Adams BW, Verma A, Daly D (1997): Activation of glutamatergic neurotransmission by ketamine: A novel step in the pathway from NMDA receptor blockade to dopaminergic and cognitive disruptions associated with the prefrontal cortex. J Neurosci 17:2921-2927

Newcomer JW, Farber NB, Jevtovic-Todorovic V, Selke G, Melson AK, Hershey T, Craft S, Olney JW (1999a): Ketamine-induced NMDA receptor hypofunction as a model of memory impairment and psychosis. Neuropsychopharmacology 20:106-118

Newcomer JW, Farber NB, Selke G, Melson AK, JevtovicTodorovic V, Olney JW (1999b): Guanabenz prevention of NMDA antagonist-induced mental symptoms in healthy humans. Schizophr Res 36:311

Overall JE, Gorham DR (1962): The Brief Psychiatric Rating Scale. Psychol Rep 10:799-812

Pearlson GD (1981): Psychiatric and medical syndromes associated with phencyclidine (PCP) abuse. John Hopkins Med J 148:25-33

Radant AD, Bowdle TA, Cowley DS, Kharasch ED, RoyByme PP (1998): Does ketamine-mediated N-methyl-Daspartate receptor antagonism cause schizophrenia-like oculomotor abnormalities? Neuropsychopharmacology 19:434-444

Robertson GS, Matsumura H, Fibiger HC (1994): Induction patterns of fos-like immunoreactivity in the forebrain as predictors of atypical antipsychotic activity. J Pharmacol Exp Ther 271:1058-1066

Sams-Dodd F (1999): Phencyclidine in the social interaction test: An animal model of schizophrenia with face and predictive validity. Rev Neurosci 10:59-90

Sanger DJ (1985): The effects of clozapine on shuttle-box avoidance responding in rats: Comparisons with haloperidol and chlordiazepoxide. Pharmacol Biochem Behav 23:231-236

Schotte A, Janssen PF, Gommeren W, Luyten WH, Van Gompel P, Lesage AS, De Loore K, Leysen JE (1996): Risperidone compared with new and reference antipsychotic drugs: In vitro and in vivo receptor binding. Psychopharmacology 124:57-73

Swerdlow NR, Bakshi V, Waikar M, Taaid N, Geyer MA (1998): Seroquel, clozapine and chlorpromazine restore sensorimotor gating in ketamine-treated rats. Psychopharmacology 140:75-80

Tamminga CA, Dale JM, Goodman L, Kaneda H, Kaneda N (1990): Neuroleptic-induced vacuous chewing movements as an animal model of tardive dyskinesia: a study in three rat strains. Psychopharmacology 102:474-478

Tamminga CA, Schaffer MH (1979): Treatment of schizophrenia with ergot derivatives. Psychopharmacology 66:239-242 
Tamminga CA, Tanimoto K, Kuo S, Chase TN, Contreras PC, Rice KC, Jackson AE, O’Donohue TL (1987): PCPinduced alterations in cerebral glucose utilization in rat brain: Blockade by metaphit, a PCP-receptor-acylating agent. Synapse 1:497-504

Vollenweider EX, Leenders KL, Scharfetter C, Antonini A, Maguire P, Missimer J, Angst J (1997): Metabolic hyperfrontality and psychopathology in the ketamine model of psychosis using positron emission tomography (PET) and $\left[{ }^{18} \mathrm{~F}\right]$ fluorodeoxyglucose (FDG). Eur Neuropsychopharmacol 7:9-24

Vollenweider FX, Leenders KL (1999): A role for cortico-striato-thalamic loops in model psychoses: A PET study with FDG. Schizophr Res 36:236

Waddington JL (1990): Spontaneous orofacial movements induced in rodents by very long-term neuroleptic drug administration: Phenomenology, pathophysiology and putative relationship to tardive dyskinesia. Psychopharmacology 101:431-447

Weiler MA, Thaker GK, Lahti AC, Ross DE, Tamminga CA (1997): Effects of ketamine on eye tracking in normal controls. Schizophr Res 24:246

Weinberger DR (1995): Neurodevelopmental perspectives on schizophrenia. In Anonymous, Psychopharmacol- ogy: The Fourth Generation of Progress. New York, Raven Press, Ltd, pp 1171-1183

Weiss JM, Kilts CD (1995): Animal models of depression and schizophrenia. In Schatzberg AF, Nemeroff CV (eds), Textbook of Psychopharmacology. Washington, DC, American Psychiatric Press, pp 81-123

Weissman AD, Dam M, London EG (1987): Alterations in local cerebral glucose utilization induced by phencyclidine. Brain Res 435:29

Worms P, Broekkamp CLE, Lloyd KG (1983): Behavioral effects of neuroleptics. In Coyle JT, Enna SJ (eds), Neuroleptics: Neurochemical, Behavioral, and Clinical Perspectives. New York, Raven, pp 93-117

Zimbroff DL, Kane JM, Tamminga CA, Daniel DG, Mack RJ, Womiak PJ, Sebree TB, Wallin BA, Kashkin KB (1997): A controlled, dose-response study of sertindole and haloperidol in schizophrenia. Am J Psychiatry 154:782-791

Zukin SR, Fitz-Syage L, Nichtenhauser R, Zukin RS (1983): Specific binding of $\left[{ }^{3} \mathrm{H}\right]$ phencyclidine in rat central nervous tissue: Further characterization and technical considerations. Brain Res 258:277-284

Zukin SR, Zukin RS (1979): Specific $\left[{ }^{3} \mathrm{H}\right]$ phencyclidine binding in rat central nervous system. Proc Natl Acad Sci USA 76:5372-5376 